Rev. Estud. Ling., Belo Horizonte, v. 28, n. 1, p. 565-596, 2020

\title{
Deslocamento forçado e permanência vigiada, território e fronteira: metáforas de espaço na representação da situação de rua na Folha de S. Paulo
}

\section{Forced displacement and guarded permanence, territory and frontier: metaphors of space in the representation of homelessness in Folha de S. Paulo}

\author{
Viviane de Melo Resende \\ Universidade de Brasília (UnB), Brasília, DF / Brasil \\ resende.v.melo@gmail.com \\ http://orcid.org/0000-0002-7791-5757
}

Resumo: Este artigo apresenta resultados de projeto de pesquisa que objetivou identificar representações no jornalismo online a respeito de ações e políticas públicas voltadas à população em situação de rua. A pesquisa, realizada no âmbito dos estudos críticos do discurso (VAN DIJK, 2009; FAIRCLOUGH, 2010; VIEIRA; RESENDE, 2016) e da análise interdiscursiva de políticas públicas (RESENDE, 2018; FISCHER, 2016), considerou a Folha de S. Paulo (em sua plataforma digital, em folha.uol.com. br) para compor um corpus abrangente das notícias publicadas sobre a população em situação de rua em um período de três anos. A composição do corpus considerou as palavras-chave '(morador)(a)(es)+(de rua)', '(pessoas)(população)+(em situação)/ (de rua)', aplicadas ao buscador do veículo jornalístico. A categoria analítica que orientou o mapeamento dos dados no software NVivo foi a metáfora (CHARTERISBLACK, 2004). Neste recorte, o foco específico são metáforas espaciais utilizadas para representar os deslocamentos e permanências da população em situação de rua na cidade em textos tratando de ações e políticas públicas. As análises apontaram que sentidos metafóricos nesse corpus têm efeito de justificativa para ações e políticas públicas desumanizantes da população em situação de rua.

Palavras-chave: população em situação de rua; jornalismo online; metáfora espacial; ação e política pública. 


\begin{abstract}
This paper presents results of a research project aimed to identify representations in online journalism regarding actions and public policies towards the homeless population. The research, carried out within the context of critical discourse studies (VAN DIJK, 2009, FAIRCLOUGH, 2010, VIEIRA; RESENDE, 2016) and the interdiscursive analyses of public policies (RESENDE, 2018; FISCHER, 2016), considered Folha de S. Paulo (in its digital platform), to compose a comprehensive corpus of the published news about the homeless population in a period of three years. The composition of the corpus considered the Portuguese language keywords '(morador)(a)(es)+(de rua)', '(pessoas)(população)+(em situação)/(de rua)' applied to the journalistic vehicle search tool. Metaphor (CHARTERIS-BLACK, 2004) was the analytical category that guided the mapping of data in NVivo software. In this paper, the specific focus are metaphors used to represent the displacements and permanences of the homeless population in the city, in texts thematizing actions and public policies. The analyzes pointed out that metaphorical meanings in this corpus have a justification effect for dehumanizing actions and public policies aimed at the homeless population.
\end{abstract}

Keywords: homeless population; online journalism; spatial metaphor; action and public policy.

Recebido em 14 de maio de 2019

Aceito em 09 de outubro de 2019

\title{
Introdução
}

"nunca las percepciones y concepciones de los diseños espaciales, de la experiencia del lugar y de los apegos territoriales son independientes de la emergencia de un sujeto, individual y colectivo, en su lecho discursivo."

(Rita Segato)

Este artigo apresenta alguns dos resultados de um projeto de pesquisa que, no âmbito dos estudos críticos do discurso (VAN DIJK, 2009; FAIRCLOUGH, 2010; VIEIRA; RESENDE, 2016) e da análise interdiscursiva de políticas públicas (RESENDE, 2018; FISCHER, 2016¹),

${ }^{1}$ FISCHER, F. Where Does the Argumentation in the Design Processes of Policy Instruments. Conferência proferida. Programa de Pós-Graduação em Desenvolvimento, Sociedade e Cooperação Internacional, Universidade de Brasília, 2016. 
teve como objetivo identificar representações que circulam no jornalismo online a respeito de ações e políticas públicas (APP) voltadas à população em situação de rua (PSR). ${ }^{2}$ Foi considerado o principal jornal da cidade de São Paulo, e de tradicional circulação em âmbito nacional no Brasil: Folha de S. Paulo (em sua plataforma digital, em folha.uol.com.br), do qual se compôs um corpus abrangente das notícias publicadas sobre a população em situação de rua em um período de três anos.

Com relação direta ao projeto mencionado, desenvolvi, entre 2015 e 2017, o projeto de pesquisa "Representação midiática da violação de direitos e da violência contra pessoas em situação de rua no jornalismo online". ${ }^{3}$ Nesse projeto, a equipe que coordenei, no Laboratório de Estudos Críticos do Discurso e no Núcleo de Estudos de Linguagem e Sociedade da Universidade de Brasília, analisou 750 textos de três jornais eletrônicos (Correio Braziliense, O Globo e Folha de S. Paulo). ${ }^{4}$ Paralelamente, também venho desenvolvendo o projeto de pesquisa "Análise Interdiscursiva de Políticas Públicas". Isso me levou ao interesse especial de investigar a representação das APP dirigidas à PSR, expresso nos projetos de pesquisa a que se vincula este texto.

Este artigo responde especificamente ao objetivo de, em um corpus de 105 textos da Folha de S. Paulo (FSP) pautando APP dirigidas à PSR, investigar, por meio de análise subsidiada por software, as recorrências e padrões de representação metafórica de APP dirigidas à PSR nesses textos jornalísticos, neste caso tomando foco específico nas metáforas espaciais que representam as permanências e deslocamentos da PSR na cidade. ${ }^{5}$ Pretendi, então, por meio de análise discursiva assistida por computador, compreender como metáforas espaciais relacionam APP e PSR nos textos jornalísticos publicados entre 2011 e 2013 no portal online da FSP.

\footnotetext{
2 Projeto "Representação de políticas públicas para população em situação de rua como gestão do território: metáforas espaciais na Folha de S. Paulo" (CAPES 88881.172032/2018-01).

${ }^{3}$ CNPq 304075/2014-0.

${ }^{4}$ Sobre o Correio Braziliense, ver Resende (2016), Resende e Ramalho (2017), Resende e Gomes (2018), Ramalho e Resende (2018); sobre O Globo, ver Resende (2018); sobre a Folha de S. Paulo, ver Resende e Mendonça (no prelo).

${ }^{5}$ Em pesquisa anterior, cujos resultados parciais estão em Resende e Mendonça (no prelo), já apresentamos recorrências de avaliação e intertextualidade nesse mesmo corpus de 105 textos pautando APP voltadas à PSR na produção discursiva da FSP online.
} 
$\mathrm{O}$ artigo foi organizado em três seções. Na primeira, discuto noções de espaço e território, e o conceito de cidade revanchista. $\mathrm{Na}$ segunda, discuto os estudos críticos do discurso, associando a análise de discurso crítica e os estudos discursivos de metáfora. Na terceira, apresento a análise favorecida pelo uso de software QDA no mapeamento de categorias vinculadas à análise de metáfora. Por fim, apresento algumas considerações finais sobre a representação metafórica das permanências e deslocamentos da PSR no território da cidade de São Paulo.

A escolha por abordar especificamente dados da FSP justifica-se por ser a cidade que (des)abriga a maior população em situação de rua no país, e por nosso estudo anterior ter mostrado ser este o veículo, entre os estudados, que mais noticia APP ligadas a questões territoriais, o que nos interessa investigar pela via da categoria discursiva da metáfora. $\mathrm{O}$ interesse em investigar metáforas espaciais nesses dados decorre da ausência de abordagens cruzando os temas das políticas públicas dirigidas a pessoas em situação de rua e da gestão territorial do espaço urbano pela via discursiva. Embora haja textos em geografia crítica (SANTOS, 2006; ROLNIK, 2016; SMITH, 2012), em urbanismo (DELGADO, 2015; GARNIER, 2006), em sociologia (WACQUANT, 2005) que discutem a gestão política e policial da pobreza nas cidades, ainda não se exploraram os padrões discursivos desta relação.

\section{Território e cidade revanchista: espaço simbólico}

Um pressuposto bastante compartilhado no Brasil e repetido tantas vezes na mídia burguesa trata a situação de rua como se fosse um problema pessoal, alguma desordem da pessoa, contrariando a evidência de que a crise habitacional é um problema estrutural. Nesse discurso, a falta de moradia parece ser vista como "um fato desafortunado" que pudesse ser abordado por meio de "políticas ad hoc para as pessoas em situação de rua", sem que se enfrente a questão estrutural da falta de moradia adequada que atinge de forma muito mais abrangente as populações empobrecidas (SMITH, 2012, p. 343).

Isso inclui retiradas violentas de pessoas em situação de rua, seu encaminhamento compulsório, explícito ou velado, a instituições, seu deslocamento forçado e o constrangimento a sua permanência no espaço público, muitas vezes justificados pela ideologia da civilidade. Em nome do bem-estar de "classes civilizadas", as "classes incivilizadas" são 
constrangidas em seus direitos e forçadas a esconder-se. Assim a cidade revanchista volta-se contra essas parcelas da população cujas condições de vida jamais são postas em questão, desde que ocultas nas periferias distantes, ou invisíveis aos olhos da elite. Seu retorno ao centro da cidade, contudo, parece intolerável.

Sobre essa "centralidade periférica" na cidade de São Paulo, Nakano, Campos e Rolnik (2004) discutem a perda de peso econômico relativo do centro histórico de São Paulo, em decorrência do deslocamento desse eixo de dinamismo produtivo ao vetor sudoeste da cidade, com consequente desvalorização dos edifícios sem garagem do centro da cidade. "O centro passa, então, a ser utilizado por uma população de menor poder aquisitivo e seus espaços, ocupados pelas estratégias de sobrevivência dos segmentos empobrecidos - sem-teto, ambulantes, desempregados, moradores de rua e demais setores excluídos dos circuitos produtivos formais" (NAKANO et al., 2004, p. 138). Ao discutir as dinâmicas dos subespaços centrais da cidade de São Paulo, contudo, Nakano, Campos e Rolnik (2004, p. 154) recusam o suposto esvaziamento econômico e demográfico da região, apontando que, em que pese "o inquestionável deslocamento da centralidade dominante (pelo menos em seus setores mais visíveis) para o vetor sudoeste da cidade", isso não determinou o "esvaziamento do centro histórico, mas sim uma mudança no perfil de seus usos e usuários, configurando novos focos de dinamismo".

As classes empobrecidas, antes afastadas do centro no processo de periferização da pobreza (CALDEIRA, 2004) e gentrificação (SMITH, 2012), retornam forçadas pelos altos custos do transporte público e pelo desemprego, e ocupam setores do centro abandonados pelas elites em seu movimento ao vetor sudoeste de São Paulo. Assim se tornam visíveis e são consideradas incômodas, intoleráveis a certos setores sociais ávidos por vocalizar suas demandas, às quais os jornais burgueses tratam de conceder espaço midiático.

A relação entre o espaço urbano e o simbólico midiatizado é relevante para Rita Segato (2006) quando lembra que o cânone antropológico define espaço em referência a um plano simbólico de ordenação de sentido, em que o espaço a um só turno é a pré-condição para nossa existência (e, podemos agregar, para o transcurso do tempo) e é também essa realidade inalcançável, indefinível e indecifrável: "comprovando ser ao mesmo tempo rígido e elástico, contido e 
incontenível, narrável e inenarrável, comensurável e furtivo" (SEGATO, 2006, p. 129). Na geografia radical, Dorren Massey (2009) coincide com Segato sobre a complexidade da definição, sustentando que o conceito teórico de espaço importa à vida social e política, sendo mais complexo do que poderia parecer à primeira vista. Ela propõe três características para uma conceituação adequada de espaço: primeira, que o espaço, como produto de relações - o que inclui, ela lembra, a ausência de relações - é uma complexidade de conexões e trocas; segunda, que o espaço é a dimensão da multiplicidade, no sentido da coexistência de diferenças na simultaneidade; terceira, que o espaço está sempre em processo, sempre em construção, nunca finalizado - "há sempre relações por fazer, desfazer, refazer" (MASSEY, 2009, p. 16), e nesse sentido o espaço está sempre aberto, já que a produção do espaço é uma tarefa política.

As concepções de Segato e de Massey, então, põem em xeque a separação de tempo e espaço, abrindo uma complexidade em que o espaço é temporal, e o tempo só pode ser concebido no transcurso de uma espacialidade móvel. O espaço já não se concebe como mero cenário, como fixo e dado, como campo do já realizado; ao contrário, é continuamente em processo, produto mutável de relações e trocas, e, portanto, também de sentidos e de atribuições simbólicas.

Sobre isso, em livro que homenageia a influência de Doreen Massey na definição de espaço, Saldanha (2013) relembra que as fronteiras de um lugar sempre são definidas pelas práticas físicas para o deslocamento, por representações (por exemplo em jornais como a $F S P$ ) e por objetos materiais como muros, grades ou (relembrando a canção popular) "cercas embandeiradas que separam quintais". $\mathrm{O}$ espaço como território pressupõe as fronteiras, físicas e simbólicas, e a própria noção de território é dependente da representação, ou seja, da "apreensão discursiva do espaço" - uma apropriação política que se define em sua "delimitação, classificação, uso, distribuição, defesa e, muito especialmente, identificação" (SEGATO, 2006, p. 129). Território, nesse sentido, é o espaço fixado em uma representação que inclui a ação e a existência de sujeitos: por isso, "não é qualquer lugar, é espaço apropriado, traçado, recorrido, delimitado (...) marcado por identidade e presença, e, portanto, indissociável das categorias de domínio e poder" (SEGATO, 2006, p. 130), e da própria ideia de fronteira, de negação, de alteridade. 
Tudo isso faz do território um cenário de reconhecimento e de negação. Quando a cidade se contempla em suas dimensões territoriais, trata-se dos pertencimentos, das autorizações de trânsito e permanência, e sobretudo, talvez, das negações que se lhe opõem. A ideologia do cidadanismo é muitas vezes conclamada quando se trata de justificar desautorizações de uso da cidade a certos grupos, e diria mesmo que se trata da principal ideologia de que a $F S P$ lança mão para tratar as permanências e deslocamentos da PSR na cidade, como sugerem os dados da pesquisa aqui discutida. A oposição contra grupos sociais avaliados como 'incivilizados' serve de justificativa para sua segregação, seu deslocamento forçado, a restrição de sua liberdade. É quando a cidade revanchista se volta contra parcelas da população cujo direito à cidade parece um absurdo impensável: só podem ser enxergadas como usurpadoras de espaços pertencentes a outros grupos. Para Smith (2012, p. 325),

Este antiurbanismo revanchista representa uma reação contra o suposto "roubo" da cidade, uma desesperada defesa da falange de privilégios desafiados, envolta na linguagem populista da moralidade cívica, dos valores familiares e da segurança do bairro. A cidade revanchista expressa, acima de tudo, o terror de raça/classe/gênero sentido pelos brancos da classe média dominante (...) A cidade revanchista augura uma feroz reação contra as minorias, a classe trabalhadora, as pessoas sem teto, os desempregados.

Para expressar esses sentidos de oposição - de um lado todos os direitos, ao outro apenas os deveres, de um lado todo privilégio, ao outro sempre desconfiança - e de controle, a mídia burguesa lança mão de variados recursos discursivos. No caso da $F S P$, vamos nos ater neste artigo aos sentidos metafóricos de base espacial mapeados no corpus de 105 textos que tematizam ações e políticas públicas dirigidas à população em situação de rua.

\section{Estudos críticos do discurso e estudos de metáfora}

Já disse antes que a análise de discurso crítica (ADC) não constitui uma teoria ou um método para o estudo crítico da linguagem na sociedade, mas um corpo heterogêneo de abordagens que, embora surgidas no contexto europeu, foram amplamente aprofundadas nas incursões que 
pesquisadores/as latino-americanos/as têm feito nesse campo. Muito foi feito na América Latina na direção da ampliação do escopo dos estudos críticos do discurso e no refinamento de abordagens teóricas e metodológicas associadas a essa interdisciplina (PARDO ABRIL, 2007; PARDO, 2010), e uma característica fundamental dos trabalhos latinoamericanos é seu comprometimento no debate de relações entre discurso e abuso de poder.

Discutir poder como controle exige uma apreensão do funcionamento da linguagem na sociedade, e esse argumento sustenta a relevância dos estudos críticos do discurso (RESENDE, 2017). Grupos sociais particulares são detentores de maior poder quando são aptos a controlar ações de outros grupos (VAN DIJK, 2001), isto é, quando são capazes de definir as bases relativas para a ação social, por exemplo, controlando instituições do aparato de governança.

A consolidação de esfera pública no debate da situação de rua e na instituição de políticas públicas para sua abordagem é questão que deve ser urgentemente tratada, incluindo discussão da representação preconceituosa de pessoas em situação de rua nos meios massivos de comunicação, e seus potenciais efeitos sociais e políticos. Com base em pesquisas anteriores, sabemos que a chamada 'grande mídia' (a mídia grande) tende a representações preconceituosas da população em situação de rua (por exemplo, ver PARDO ABRIL, 2008; ver também os capítulos publicados em PASCALE, 2013 e em MONTECINO, 2018, e os artigos publicados nos Cadernos de Linguagem e Sociedade, vol. 13, número monográfico). Reconhecida a ação midiática para a consolidação de formas de representar e interpretar a realidade, essas representações, muitas vezes repetidas em diferentes tipos de textos, também têm efeitos potenciais nos modos como agimos em relação à situação de rua, e principalmente como compreendemos as APP dirigidas à PSR. A repetição de representações pejorativas e sua aceitação pela sociedade, servindo de base para preconceito, poderiam explicar, ao menos em parte, a ausência de políticas eficazes na superação da situação de rua e a aceitação social de políticas violentas?

É no discurso que se exercem as pressões que atuam na definição de uma agenda pública; em ambientes discursivos - da mídia, da política, dos movimentos sociais - constrói-se e reconstrói-se essa agenda e os embates discursivos que promovem a avaliação de suas possibilidades. Assim, os modos como se orienta e se organiza o debate público em 
torno de um problema são questões discursivas, que, portanto, podem ser adequadamente abordadas por meio dos estudos discursivos.

Nos termos de Souza (2006, p. 30), uma pesquisa em políticas públicas pode se perguntar "como se constrói a consciência coletiva sobre a necessidade de se enfrentar um dado problema”. A percepção/ construção de uma questão social - como a situação de rua - na agenda política é fator primordial para que se considere a relevância da abordagem política dessa questão, e a natureza dessa abordagem - pelo viés da assistência, da participação ou da repressão - também é decorrente da compreensão social da questão.

A "consciência coletiva" de que nos fala Souza (2006) também remete ao que van Dijk (2009, p. 6) discute como dimensão intersubjetiva derivada das experiências de socialização que compartilhamos como grupos sociais, e que levam a "vários tipos de conhecimento compartilhado e outras crenças". Esse compartilhamento de sentidos estabiliza modos de compreensão das questões sociais, incluída a situação de rua e as APP julgadas adequadas como respostas a ela, o que pode ser investigado pela via discursiva, por meio de mapeamentos discursivos em distintos campos sociopolíticos, como a lei, a mídia, os movimentos sociais e políticos. No caso da pesquisa de que este artigo se recorta, os dados de um jornal de circulação massiva, em sua plataforma de distribuição online, são tomados como elementos chave para a compreensão de sentidos que modelam a percepção da PSR na cidade de São Paulo, e consequentemente impactam sobre as respostas públicas à situação de rua. Com um corpus de notícias tematizando APP dirigidas à PSR, o acesso a esses sentidos é ainda mais privilegiado.

A análise de notícias como material empírico para a abordagem de problemas sociais como as representações de APP voltadas à situação de rua justifica-se também porque, nos estudos críticos do discurso, entende-se que a notícia reorganiza séries de eventos relatados fora de sua ordem lógica e cronológica, e por isso é uma forma de regulação social. Assim, para Fairclough (2003), a produção de histórias em notícias é reconstrução de acontecimentos fragmentários como eventos distintos e separados, incluindo certos acontecimentos e excluindo outros, assim como organizando esses eventos construídos em relações particulares. Sobre relações entre grupos minorizados e a produção de notícias, van Dijk (2005, p. 42) destaca que 
as atitudes a respeito de alguns grupos e as opiniões sobre fatos específicos podem influir na escolha léxica de palavras (...) as minorias são frequentemente representadas em um papel passivo (as coisas se decidem, se fazem etc. para ou contra elas), a não ser que sejam agentes de ações negativas, como delinquência, entrada ilegal, violência ou consumo de drogas. Neste último caso, sua responsabilidade será enfatizada.

A produção de notícias, portanto, é um processo interpretativo e construtivo, e não simplesmente um relato 'dos fatos'. Notícias também podem ter 'uma 'intenção explanatória' relacionada à 'focalização': dar um sentido a eventos colocando-os em uma relação que incorpora um ponto de vista particular" (FAIRCLOUGH, 2003, p. 84-85). Nos estudos críticos do discurso, portanto, textos noticiosos são compreendidos como parte do aparato de governança, porque notícias são orientadas para a regulação e o controle de eventos e da maneira como as pessoas reagem a eventos.

$\mathrm{Na}$ realização das práticas em eventos, como sustenta Fairclough com base em Bhaskar (1998), pessoas carregam sua prévia compreensão das práticas - fruto de sua socialização e dos conhecimentos compartilhados resultantes, como sustenta van Dijk. A abordagem relacional e a abordagem sócio cognitiva, a meu ver, não se contradizem, ao contrário, se complementam mutuamente, permitindo uma compreensão mais complexa das dinâmicas estruturais e interativas que só são possíveis, obviamente, porque pessoas de carne e osso, mente e espírito interagem de forma estruturada, num movimento em que constroem e reconstroem formas de compreensão do mundo e das coisas. Essa possibilidade de diálogo teórico entre as duas perspectivas discursivo-críticas é possível porque o realismo crítico de Bhaskar, que serve de base à abordagem dialético-relacional proposta por Fairclough (2010), não nega a construção discursiva da realidade, não recusa o fato de que as coisas sociais são afetadas pelos processos de construção do conhecimento, e a abordagem cognitiva de que se serve van Dijk (2009) tampouco é radical numa postura mentalista, pois entende que a cognição é um processo social. Assim, sendo as duas abordagens moderadas em suas posturas realista (crítica) e (sócio) cognitiva, mantêm entre si a coerência necessária para sua articulação, o que é útil à complexidade da análise de metáfora. 
A categoria analítica central aqui tomada como foco para mapeamento em software é a metáfora. Em estudo clássico sobre o tema, Lakoff e Johnson (1980) sustentam que nosso sistema conceitual é metafórico por natureza: os conceitos que estruturam os pensamentos estruturam também o modo como percebemos o mundo, a maneira como nos comportamos no mundo e o modo como nos relacionamos com outras pessoas de acordo com nossa experiência física e cultural. Metáforas realçam ou encobrem certos aspectos do que representam Fairclough (2001) registra que, quando significamos algo por meio de uma metáfora, filiamo-nos à maneira particular de representar aspectos do mundo traduzida na imagem metafórica produzida. Daí a relevância do foco na análise de metáforas, no caso específico deste estudo, especialmente quando consideramos, com Charteris-Black (2004, p. 23), que as metáforas "são cruciais no processo de influenciar o caminho em que problemas sociais são conceituados".

A metáfora sempre foi de interesse dos estudos de linguagem, desde a retórica clássica, e também chamou atenção da estilística e dos estudos literários. Para a ciência linguística, tornou-se objeto sistemático de interesse apenas no último quarto do século XX. Um marco dessa virada no estudo linguístico de metáforas, extrapolando seus aspectos retóricos e estéticos, foi a realização do simpósio "Metáfora: o salto conceitual", em 1978, na Universidade de Chicago. Reconhecendo a metáfora como conceito "essencialmente controverso e polêmico" (COWAN; FEUCHTHAVIAR, 1992, p. 7), a universidade recebeu pensadores como Donald Davidson, Paul Ricoeur, Nelson Goodman, Max Black, entre outros, que conduziram acalorado debate a respeito do conceito e seus aspectos linguísticos (cognitivos, semânticos e pragmáticos).

Com seu livro de 1980, Lakoff e Johnson lançaram bases para a mais influente teoria de metáfora na linguística desde então: a teoria da metáfora conceitual (TMC). Segundo Dancygier (2016), desde essa obra a metáfora tem sido discutida em termos de mapeamento conceitual conectando dois domínios, o que permitiria a abordagem de fenômenos abstratos ou emoções em termos de experiências concretas ou corpóreas. Ela explica:

o conceito de domínio (...) se refere a um pacote conceitual, incluindo uma série de elementos conectados (...). Por exemplo, um domínio de Guerra inclui uma série de componentes, como oponentes, armas, ataque e defesa, vitória e derrota. Esses 
componentes podem ser usados como base para uma série de expressões metafóricas representando, de modo geral, o domínio da Discussão (uma troca de pensamentos assumindo alguma discordância inicial, e vários procedimentos e resultados desses procedimentos). Ao falar sobre uma discussão em termos de guerra (atacar a posição de alguém, ganhar uma disputa etc.), o domínio da Guerra é a fonte da estrutura, enquanto a Discussão é o domínio alvo. Com base nisso, um mapeamento metafórico pode ser definido como uma relação entre dois domínios conceituais (o domínio fonte e o domínio alvo) que estabelece ligações (mapeamentos) entre elementos específicos das duas estruturas. (DANCYGIER, 2016, p. 29)

Assim, nessa perspectiva conceitual e cognitiva, trata-se de um domínio mais abstrato da experiência ser compreendido em termos de um domínio mais básico ou mais concreto, que fornece as bases para a interpretação da experiência, e também para sua expressão simbólica na linguagem. Em diversas teorias, mais ou menos radicais nessa conceituação da experiência em termos de domínios, é relevante a noção de corporificação da experiência (embodiment), em que conceitos mais abstratos são construídos com base em experiências corpóreas.

Lakoff e Johnson (1980) distinguem entre metáforas ontológicas e orientacionais; estas últimas "associadas à corporeidade e à maneira como nosso ser biológico permite a estruturação de nosso ser social", de modo que a "noção de espacialidade - dentro/fora, acima/abaixo, [na] frente/ [a]trás - e de como ocupamos com nossos corpos essa espacialidade, como a experienciamos, constrói espaços de significação pelo movimento metafórico" (ACOSTA, 2018, p. 24).

Li (2016) chama atenção para tensões entre a TMC e a ADC, pois a primeira argumenta que a metáfora seria uma questão de linguagem e cognição, enquanto a ADC se ocupa centralmente com questões sociais e políticas do discurso. Além disso, conforme Li (2016), a TMC contradiz a ADC porque para esta as metáforas têm um aspecto pragmático central, vinculado a propósitos comunicativos situados em eventos discursivos e seus efeitos potenciais. Mendes e Nascimento (2010, p. 96) também reconhecem essas tensões, sugerindo que a TMC, ao analisar processos metafóricos como operações cognitivas de estruturação de certos domínios em termos de outros, não se interessa diretamente pelos aspectos de "processamento discursivo e de suas variáveis situacionais, pragmáticas". 
A análise de metáfora, então, parece exigir uma maior complexidade teórica, em que o aspecto cognitivo não deve ser ignorado, mas tampouco explica todo o processo. Se as metáforas expressam atitudes em relação aos domínios mapeados - no que concordam todas as teorias de metáfora estudadas - e se "atitudes são essencialmente sociais" e, portanto, "não devem ser confundidas com opiniões pessoais", porque são "compartilhadas por membros de grupos sociais" com suas "identidades, ações, normas e valores, relações com outros grupos e recursos" (VAN DIJK, 2014, p. 129), então os aspectos cognitivos e os pragmáticos, vinculados aos interesses em jogo, precisam ser considerados em sua relação.

Para Charteris-Black (2004, p. 7), "a metáfora é um conceito relativo, que não pode ser definido a partir de apenas um critério aplicável a todas as circunstâncias, e sua definição precisa incluir critérios linguísticos, pragmáticos e cognitivos". Por isso, para ser útil aos estudos críticos do discurso, a abordagem semântica cognitiva formulada por Lakoffe Johnson precisa ser complementada com uma análise de fatores pragmáticos, que não perca de vista o fato de as metáforas serem usadas em situações discursivas que definem seu papel.

Apesar das tensões teóricas, Li (2016) reconhece na TMC a relevância da distinção entre metáforas conceituais (ou conceitos metafóricos) e metáforas linguísticas (ou expressões metafóricas). Em suas palavras, "a metáfora [conceitual] é um modo de pensar, e as expressões metafóricas são sistematicamente motivadas por metáforas conceituais subjacentes" (LI, 2016, p. 93). Isso implica que, teoricamente, "uma única ideia [metáfora conceitual, nos termos de Lakoff e Johnson] explica um número de expressões metafóricas" (CHARTERIS-BLACK, 2004, p. 9), o que pode significar uma economia explicativa para a análise de metáforas realizadas em textos. Em sua proposição de uma análise crítica da metáfora, Charteris-Black (2004) sustenta um nível conceitual hierarquicamente organizado em chaves conceituais, metáforas conceituais e metáforas.

Em seus termos, indo do mais concreto ao mais abstrato, metáforas são representações linguísticas resultantes de alguma mudança no uso de uma palavra ou frase em contexto específico, causando tensão semântica - ou seja, trata-se de expressões metafóricas situadas; metáforas conceituais referem-se a afirmações que resolvem a tensão semântica de um conjunto de metáforas, mostrando que estão relacionadas a uma mesma compreensão, de modo semelhante ao que Lakoff e Johnson (1980) propõem; e chaves conceituais, por sua vez, 
explicam conjuntos de metáforas conceituais em relação a discursos particulares. Na definição de Charteris-Black (2004, p. 244, destaques acrescentados), apropriada neste estudo:

\begin{abstract}
metáforas conceituais e chaves conceituais são inferências abstratas a partir da evidência linguística fornecida por metáforas particulares. Não há realidade para elas, a não ser como modelos de trabalho [...]. O objetivo de inferir metáforas conceituais a partir de metáforas de superfície é permitir identificar padrões de inter-relação entre metáforas que explicam seu significado. Da mesma forma, inter-relacionar metáforas conceituais através da identificação de chaves conceituais pode ajudar a avaliar a coerência de discursos particulares. A identificação e descrição desses níveis conceituais aumenta nossa compreensão de seu papel ideológico.
\end{abstract}

Assim, Charteris-Black (2004) sustenta o argumento da economia analítica, quando defende a vantagem de se considerarem muitas metáforas particulares (expressões linguísticas metafóricas) em sua referência a um menor número de metáforas conceituais e a um número ainda menor de chaves conceituais. Essa é a perspectiva escolhida para o estudo, e por isso na estrutura de nós de codificação que construí para a organização dos 105 textos da FSP no software, esse argumento foi considerado, como discutirei na próxima seção.

\title{
3 Situação de rua e território: um olhar para os dados
}

Para explorar representações metafóricas de APP voltadas à PSR na FSP, foi conduzida uma investigação documental que incluiu a análise discursiva com auxílio de pacote QDA - software para análise qualitativa de dados, neste caso o NVivo11 Pro, conforme explicamos em Resende e Ramalho (2017). A pesquisa documental utiliza, como principal material empírico, dados de natureza formal, como textos midiáticos, cuja elaboração demanda competência de conhecimento especializado (tecnologias discursivas). Nos termos específicos da pesquisa, o foco foi a representação de APP dirigidas à PSR, conforme representadas em textos publicados pela FSP em seu portal online. Nas três subseções a seguir, explico como foram realizadas as análises de metáforas sobre APP e sobre a PSR nos 105 textos que compõem esse recorte de corpus da FSP e pontuo alguns dos resultados dessas análises. 


\subsection{Mapeamento de metáforas no corpus}

Com base nas palavras-chave '(morador)(a)(es)+(de rua)', '(pessoas)(população)+(em situação)/(de rua)', aplicadas ao buscador do veículo jornalístico, foram mapeados e coletados todos os textos publicados sobre a PSR no período de três anos compreendido entre 2011 e 2013 que retornaram nessa busca. Da FSP, foram coletados 456 textos publicados sobre a PSR no intervalo considerado, e todos eles foram organizados na plataforma do software. Os textos da FSP foram classificados em 11 temáticas, e deles 105 pautam a temática de APP (uma discussão pormenorizada dos procedimentos no corpus da FSP poderá ser acessada em Resende e Mendonça, no prelo).

O uso do software teve como propósito a organização qualitativa dos dados e a primeira análise do corpus, além de orientar a realização dos recortes de dados a serem submetidos à análise discursiva crítica mais fina, considerada a impossibilidade de se submeter um corpus extenso ao escrutínio analítico da ADC. A vantagem de se trabalhar com recortes decorre de que as formulações para análise textual da ADC referem-se a "um trabalho intensivo que pode ser produtivamente aplicado a recortes de material de pesquisa mais que a corpora extensos" (FAIRCLOUGH, 2003, p. 6). Assim, as ferramentas do NVivo foram úteis para a classificação temática dos 456 textos coletados, para a percepção de padrões e recorrências representacionais da ação pública no corpus de 105 textos tematizando APP e, no interesse específico deste trabalho, para o mapeamento amplo das metáforas sobre a PSR e sobre as APP presentes nesse corpus, incluídas as metáforas espaciais que são o foco bem específico deste artigo.

Esclareço que no mapeamento de metáforas que passo a apresentar não foram consideradas as chamadas metáforas convencionais, ou 'metáforas mortas'. De acordo com Charteris-Black (2004, p. 17), metáforas convencionais estão "em algum ponto intermediário entre usos literais e metafóricos - refletem um processo diacrônico pelo qual o uso que era originalmente 'metafórico' se torna estabelecido como 'literal' dentro de um idioma”'. Assim, são metáforas 'automáticas', que embora possamos reconhecer como metáforas em um sentido amplo, acrescentam pouco à análise representacional, por seu caráter automatizado de uso 
em colocações. ${ }^{6}$ Um segundo esclarecimento quanto ao mapeamento de metáforas nesses 105 textos é que foram mapeadas apenas as metáforas referentes à PSR ou às APP a ela dirigidas. Metáforas referentes a outros temas no corpus não entraram, então, em nosso mapeamento. Essas duas decisões visaram preservar nossa atenção no foco específico, favorecendo a composição de um corpus de metáforas homogêneo e relevante aos fins da pesquisa.

O primeiro passo para a utilização do pacote QDA escolhido foi criar uma estrutura de nós (categorias) para codificação inicial dos dados. Os nós analíticos iniciais foram de dois tipos: os nós temáticos de preenchimento indutivo sequencial à leitura dos textos, e os nós motivados pelas teorias de metáfora estudadas. Os nós analíticos teoricamente motivados foram, na categoria de Metáfora, domínio básico, esquema de imagem e metáfora complexa; na categoria Outros tropos, metonímia, ofuscação/ eufemismo, personificação e símile; e, na categoria Modificação, criação de novo sentido e modificação por adjetivação.

Das categorias motivadas por teorias de metáfora, neste artigo abordarei apenas as metáforas de esquema de imagem. Os esquemas de imagem poderiam ser interpretados como tipo mais específico de metáfora básica, ${ }^{7}$ em que a fonte de mapeamento para domínios abstratos deriva da interação corporal cotidiana no mundo físico, gerando interpretações de experiência baseadas em esquemas de contenção (entrada/ saída; dentro/ fora; centro/ periferia), esquemas de orientação (embaixo/ em cima; na frente/ atrás) e esquemas de movimento (fonte, meta, caminho). Esses foram os mapeamentos metafóricos mais relevantes no corpus.

\footnotetext{
${ }^{6}$ Um exemplo de metáfora convencional retirado do corpus poderia ser o trecho "A Prefeitura de Ribeirão Preto (313 km de São Paulo) fará um recenseamento do número de moradores de rua do município, mas já admite a alta dessa população". Embora "alta dessa população" seja evidentemente uma metáfora orientacional, baseada em esquema de imagem alto/baixo, seu caráter convencional limita sua relevância analítica. ${ }^{7}$ Lembremos com Dancygier (2016, p. 37) que "[m]etáforas primárias são diretamente enraizadas em nossa experiência básica e servem de base para metáforas mais complexas, socialmente motivadas e culturalmente específicas". Assim se distinguem as metáforas de domínio básico e as metáforas complexas, tipologia em que as metáforas de domínio básico dizem respeito à experiência básica concreta, com sensações ligadas ao espaço, à matéria, à temperatura -, e essas experiências servem como input para mapeamentos de experiências mais abstratas.
} 
O software utilizado não faz análises automáticas, sendo uma ferramenta qualitativa. Assim, foi necessário proceder à leitura cuidadosa de todos os 105 textos e a sua codificação foi feita manualmente. Nesse processo, foram indutivamente levantados os nós temáticos, com o objetivo de depois poder cruzar os temas representados por metáforas e os tipos de metáforas discutidos nas teorias e mapeados no corpus. Numa segunda etapa de leitura dos trechos codificados, as temáticas foram refinadas e reduzidas às 10 consideradas nas análises, apontadas no quadro a seguir:

QUADRO 1 - Nós temáticos indutivamente atribuídos, em sua visualização na tela do software

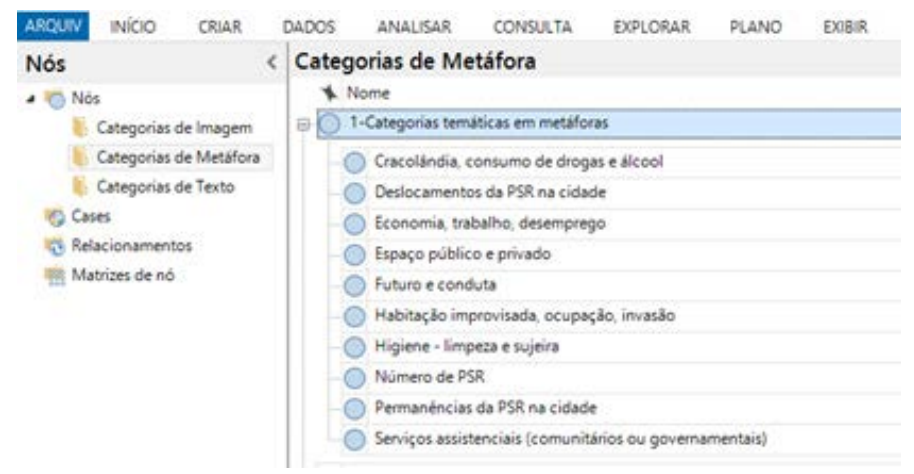

Os temas mais representados por meio de mapeamentos metafóricos, tanto por número de textos em que ocorriam quanto por número de ocorrências, foram a chamada "cracolândia" e o consumo de álcool e outras drogas (79 ocorrências de metáforas em 35 textos), os serviços assistenciais governamentais ou comunitários (79 ocorrências em 33 textos), e os deslocamentos da PSR na cidade (65 ocorrências em 35 textos). Na próxima subseção, mostrarei um panorama representacional dessa última temática, seguindo a ferramenta nuvem de palavra, baseada na densidade lexical em recortes de dados, e complementarei com dados da representação metafórica da permanência de PSR em espaços urbanos (23 ocorrências de metáforas em 18 textos). 


\subsection{Densidade lexical em recortes temáticos: deslocamentos e permanências da PSR na cidade}

As nuvens de palavras geradas a partir de codificações temáticas são elucidativas das abordagens de temas em um corpus. Para a composição das nuvens de palavra a seguir, foram consideradas as trinta palavras mais frequentes nos recortes temáticos 'deslocamentos da PSR na cidade" e, na nuvem seguinte, "permanências da PSR na cidade". O tamanho e disposição mais central ou mais periférica de cada palavra na nuvem é indicativo de sua densidade proporcional no recorte. Tendo sido consideradas apenas palavras com no mínimo quatro letras, a palavra 'rua' não aparece, mas é o padrão de colocação mais frequente com morador(es).

O princípio da apreciação da nuvem não é quantitativo - se assim fosse, seria mais indicada uma simples contagem de ocorrências, o que o pacote QDA utilizado também entrega facilmente. Uma nuvem de palavras favorece visualização da densidade relativa de palavras relevantes num conjunto de dados - a nuvem em si não produz análise, pois as palavras estão isoladas; contudo, a partir da visualização na nuvem e da ferramenta "Resumo", também possibilitada a partir da pesquisa de frequência de palavras no software, é possível acessar as colocações/ situações em que certas palavras ocorrem, e aí está o interesse analítico.

Vejamos a primeira nuvem:

FIGURA 1 - Nuvem das 30 palavras mais frequentes na temática "Deslocamentos da PSR na cidade"

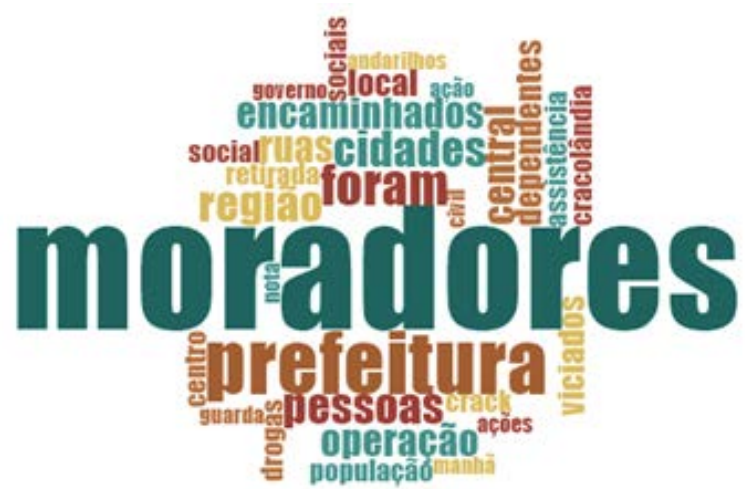


A palavra mais frequente nesse recorte é 'moradores', que aparece em colocação com "de rua” em todas as ocorrências. É seguida por 'prefeitura', termo principalmente utilizado como Ator de processos materiais - como em "Prefeitura faz operação para retirar moradores de rua acampados no MASP”, "A Prefeitura de São Paulo realizou ontem uma operação para a remoção de moradores de rua acampados na praça da Sé", "APrefeitura do Rio de Janeiro, acompanhada pela Polícia Militar, realizou na manhã desta sexta-feira uma ação de combate ao crack e de retirada de moradores de rua na região de Madureira", "Nesta semana, a prefeitura e a Polícia Militar iniciaram ações para retirá-los das calçadas do Brás" - e como Dizente em processos verbais - como em "governo do Estado e a Prefeitura de SP discutem a ideia de enviar frequentadores da cracolândia", "A Prefeitura de Belo Horizonte esclarece que não existe e jamais existiu de sua parte nenhuma orientação voltada para a prática de remoção compulsória", "A prefeitura reagiu com nota lacônica ao surgimento da "favelinha", "Prefeitura promete tirar moradores de rua acampados no MASP" (destaques acrescentados).

No primeiro caso, o dos processos materiais, o padrão é bastante estável, com 'fazer/ realizar/ iniciar' + 'ações/ operações' + 'em um território definido'. O caso dos verbos de dizer é mais diverso, incluindo atos de justificativa, explicação e promessa - em todos eles, contudo, é possível depreender um sentido de resposta à sociedade a respeito de ações questionadas ou exigidas pela sociedade, sendo, portanto, atos de resposta a que a FSP cede espaço. Os casos apresentam metáforas recorrentes de 'retirada' e 'remoção', que compreendem uma possível 'solução' para a questão da situação de rua baseada na noção de espacialidade dentro/fora: a PSR estando 'dentro' de um espaço que se configura como problema, deve ser posta 'fora', retirada, removida deste espaço.

A alta densidade de 'foram' nesse recorte temático lembra a análise da representação de APP em textos publicados em $O$ Globo, também parte do projeto que origina este artigo (RESENDE, 2018). Aqui, como lá, trata-se de um padrão de colocação em que pessoas em situação de rua são representadas como alvo de ações realizadas por outros atores: na representação da $F S P$, sofrem a ação de serem recolhidas, tiradas, encaminhadas, retiradas e até removidas e devolvidas, em expressões que não apenas as representam de forma passiva, mas também as desumanizam, ao utilizar em sua referência léxico reservado a objetos (como 'devolver'). 
O foco no espaço nesta nuvem também se realiza nos termos 'cidades' (por exemplo, "devolver andarilhos às suas cidades de origem"), 'região' (quase exclusivamente "região central"), 'local' (por exemplo, "em local bem longe da vista"), 'centro' (mormente centro de São Paulo e centro da capital), 'cracolândia' ("não resolve a questão da cracolândia. Ela vai para outro submundo", "nova esperança para que a cracolândia não seja removida só geograficamente", "circular a qualquer momento na cracolândia", "polícia expulsou os viciados da cracolândia e eles passaram a perambular") e 'retirada' ("de comunidades carentes", "de moradores de rua", "compulsória de pessoas que vivem nas ruas", "de mendigos das ruas").

As representações de deslocamentos da PSR na cidade são representações de um movimento forçado, vigiado, operado por outros atores, associado centralmente às ações do executivo municipal. Quanto a sua permanência em um local, vejamos a nuvem das 30 palavras de quatro ou mais letras com maior densidade nessa temática:

FIGURA 2 - Nuvem das 30 palavras mais frequentes na temática "Permanências da PSR na cidade"

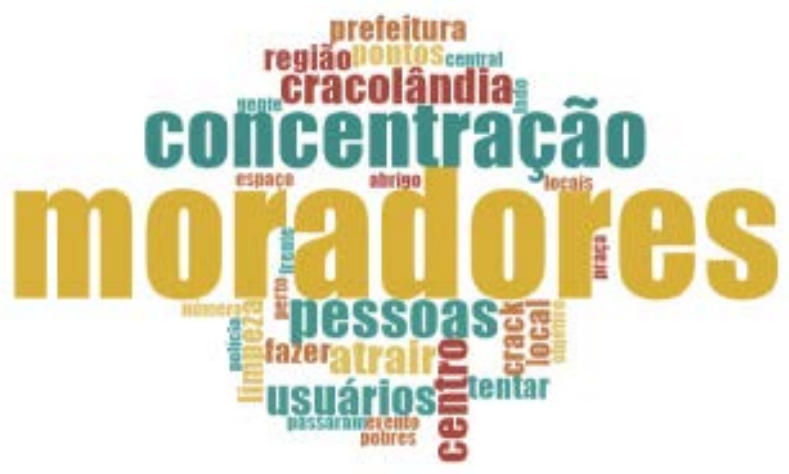

Aqui também a palavra mais frequente é "moradores", que na maior parte de suas ocorrências está em colocação com "de rua", havendo apenas três exceções: dois casos (em um mesmo texto) em que o item "moradores" sem complemento serve de referência a pessoas em situação de rua ("intensificar as ações das rondas e abordagens sociais nos pontos de maior concentração de moradores para tentar diminuir o número de 
pessoas nessa situação" e "A limpeza dos pontos de concentração de moradores é outra estratégia para tentar dispersar esse público") e um caso de referência a moradores locais ("moradores relatam que com $\underline{\text { a }}$ chegada da tenda a sensação de insegurança aumentou"). No primeiro caso, é de notar que as duas instâncias em que "moradores" se separa de "de rua" na referência à PSR a colocação seja com "concentração de", o que deixa uma pista de leitura capaz de mitigar a possível ambiguidade.

Concentração, nesse recorte temático, é a segunda palavra em densidade. É a metáfora mais produtiva no corpus para referir a permanência da PSR em um local. Todas as ocorrências da palavra seguem o mesmo padrão: 'concentração de' + 'item nominal de referência à PSR', como em "local de concentração de pessoas que se drogam", "Concentração de morador de rua 'assusta", "grande concentração de usuários de crack", "pontos de maior concentração de moradores", "um dos pontos de concentração de moradores de rua", "A concentração de pessoas em situação de rua" e "A limpeza dos pontos de concentração de moradores é outra estratégia para tentar dispersar esse público". Neste último caso, a metáfora química de concentração guarda coerência com a de dispersão. É recorrente a presença do foco espacial com "ponto de concentração" ou "local de concentração", o que pode sustentar a interpretação de que a situação de rua seja percebida como problemática em relação a certos espaços específicos, não como questão social.

Outra metáfora produtiva, esta de ordem biológica (e animalizante), é a de atração. Nos casos em que ocorre a palavra "atrair", observase a colocação com "moradores de rua", "mendigos" ou "pessoas indesejáveis". Quando a ação de atrair tem como origem a prefeitura, refere-se a serviço disponibilizado, como em "tentar atrair os moradores de rua para albergues da prefeitura, desocupando assim praças e ruas" - e é notável que essa 'atração' tenha por objetivo justificado a desocupação de praças, e de novo o foco é espacial, não social. Mas quando a 'atração' referida tem polo negativo, trata-se de referir ações de impedimento que são sempre expressas em articulações intertextuais da voz de moradores e trabalhadores locais, como em "Para o jornaleiro Fabio Filgueira, 28, que trabalha próximo à estação Carandiru, a rua fica mais bonita com o gradil e as plantas que foram colocadas ali. 'Eu mesmo não reformo o toldo da minha banca para não atrair mendigos à noite." ou em "Acho louvável a atitude da igreja em ajudar os pobres, e a gente colabora sempre que possível, mas aqui ao lado vai atrair pessoas indesejáveis" 
(sobre as avaliações presentes em articulações intertextuais de vozes de moradores e trabalhadores locais, ver análises em Resende e Ramalho, 2017, e em Resende e Mendonça, no prelo).

Se juntarmos a isso as ocorrências de "cracolândia", "usuários" e "crack" nesse mesmo nó temático - também palavras de nossa nuvem -, observamos sentidos de expulsão (como em "Desde que a polícia expulsou os viciados da cracolândia e eles passaram a perambular"), também expressos pela metáfora da migração ("há uma grande concentração de usuários de crack no local que migraram da cracolândia, também na região central"). Metáforas desumanizantes nesses casos são por exemplo as de 'espalhar' ("Moradores de rua e usuários de crack se espalharam pelo centro desde o início do ano") e seu contrário 'agrupar' ("Era lá que centenas de usuários se agrupavam para consumir a droga"), que interpretam a PSR como objetos.

Assim, as metáforas produtivas na temática de permanências da PSR são de fato formas de argumentar em favor de seu deslocamento forçado ou de sua inadmissibilidade em certos espaços urbanos.

\subsection{Metáforas conceituais e chaves conceituais}

Realizado todo o mapeamento de expressões metafóricas no corpus de 105 textos da FSP tematizando APP dirigidas à PSR, o passo subsequente foi sua organização em metáforas conceituais. Segui a conceituação de Charteris-Black (2004), que considera metáforas conceituais como afirmações que resolvem a tensão semântica de um conjunto de metáforas, estas últimas sendo as expressões linguísticas que têm existência real em textos. Desse modo, as metáforas conceituais não coincidem com as metáforas mapeadas, pois são instrumentos epistemológicos para sua ordenação e análise.

Nos 105 textos do corpus, consideradas todas as temáticas delimitadas, foram mapeadas 431 expressões metafóricas, ordenadas em 48 metáforas conceituais, a saber: 
QUADRO 2 -As 48 metáforas conceituais no corpus organizadas por domínio metaforizado

\begin{tabular}{|c|c|}
\hline A CIDADE É & SER VIVO \\
\hline ÁLCOOL OU DROGA É & ESPAÇO \\
\hline AÇÃO OU POLÍTICA PÚBLICA É & $\begin{array}{l}\text { BASE DE APOIO } \\
\text { CAMINHO } \\
\text { ENGRENAGEM } \\
\text { OÁSIS NO DESERTO } \\
\text { SEDUÇÃO OU ATRAÇÃO } \\
\text { SER VIVO } \\
\text { VITRINE OU MAQUIAGEM }\end{array}$ \\
\hline APP OU SITUAÇÃO DE RUAÉ & GUERRA OU DESAFIO \\
\hline CRACK É & EPIDEMIA \\
\hline CRACOLÂNDIA É & $\begin{array}{l}\text { CIRCULAÇÃO } \\
\text { CONCENTRAÇÃO } \\
\text { ESCURIDÃO } \\
\text { ESPETÁCULO OU JOGO } \\
\text { FENÔMENO } \\
\text { OBJETO } \\
\text { SER VIVO } \\
\text { SOM } \\
\text { SUBMUNDO } \\
\text { TERRITÓRIO } \\
\text { MÁQUINA }\end{array}$ \\
\hline FECHAR CENTRO SOCIAL É & DAR AS COSTAS OU CRUZAR BRAÇOS \\
\hline GENTRIFICAÇÃO É & REVITALIZAR \\
\hline O OLHAR DO OUTRO É & AMEAÇA \\
\hline O SOCIAL É & UM LUGAR DE ONDE SE PODE ENTRAR E SAIR \\
\hline PESSOA EM SITUAÇÃO DE RUA É & $\begin{array}{l}\text { DONO DA RUA } \\
\text { GASTO } \\
\text { OBJETO } \\
\text { PERIGO } \\
\text { PROBLEMA }\end{array}$ \\
\hline PSR OU SITUAÇÃO DE RUA É & $\begin{array}{l}\text { INVISÍVEL } \\
\text { SUJEIRA }\end{array}$ \\
\hline PSR OU USUÁRIO DE CRACK É & ANIMAL \\
\hline
\end{tabular}




\begin{tabular}{l|l}
\hline & ABANDONO SOCIAL \\
& CONCENTRAÇÃO \\
& DEGRADAÇÃO \\
& DOENÇA \\
SITUAÇÃO DE RUA É & ESCONDERIJO \\
& ESPAÇO \\
& ESTAR SEM RUMO OU PERDIDO \\
& HOSPEDARIA, MORADIA, ALUGUEL \\
& INVASÃO HUMANA \\
& JAULA OU CORRENTE \\
& LIBERDADE \\
& MARCA \\
\hline \multirow{2}{*}{ USUÁRIO DE CRACK É } & OBJETO \\
& INIMIGO A SER COMBATIDO \\
\hline
\end{tabular}

Para chegar a essas metáforas conceituais, o que fiz foi abrir uma por uma as 431 expressões metafóricas e, relendo-as, agrupei-as de acordo com as metáforas conceituais que resumiam as tensões semânticas que provocavam, conforme os domínios mapeados em cada caso.

No caso do nó de interseção 'deslocamentos + permanências da PSR na cidade' $x$ 'esquema de imagem', e lembrando que para um mesmo texto diversas expressões metafóricas e metáforas conceituais podem ter sido mapeadas, o cruzamento dos casos da interseção com os levantamentos de metáforas conceituais mostra que, nesse conjunto de dados, as metáforas conceituais mais recorrentes, considerando apenas as interseções com valores iguais ou superiores a cinco, são:

TABELA 1 - Consulta em matriz de codificação: células de interseção mais produtivas $(>5)$ em Metáforas conceituais $x$

(Deslocamentos + Permanências $x$ Esquema de Imagem)

\begin{tabular}{l|c}
\cline { 2 - 2 } & $\begin{array}{c}\text { Interseção: Deslocamentos + } \\
\text { Permanências / Esquema de Imagem }\end{array}$ \\
\hline “CRACOLÂNDIA” É CONCENTRAÇÃO & 8 \\
\hline POLÍTICA PÚBLICA É CAMINHO & 37 \\
\hline POPULAÇÃO EM SITUAÇÃO DE RUA É OBJETO & 5 \\
\hline SITUAÇÃO DE RUA É CONCENTRAÇÃO & 6 \\
\hline SITUAÇÃO DE RUA É ESPAÇO & 37 \\
\hline
\end{tabular}


Quando se trata dos deslocamentos e permanências da PSR na cidade, o tipo preferencial de metáfora, como vimos, é o esquema de imagem, e a representação de APP voltadas para a PSR nesse corpus da FSP tende a uma representação em que a população em situação de rua é objeto sobretudo de políticas de encaminhamento. Seus movimentos representados são mais que nada movimentos forçados, que se repetem e se justificam exaustivamente na FSP, também pelo recurso da representação de suas permanências com avaliação negativa. Se considerarmos os resultados de metáforas conceituais nesse nó de interseção, temos algumas justificativas que nesses textos se expressam para ações repressivas, tomadas em termos de territorialidades.

Na proposta metodológica de Charteris-Black (2004), de que me aproprio aqui conforme a necessidade apontada nos dados que analiso, chaves conceituais ajudam a explicar conjuntos de metáforas conceituais em relação a discursos particulares, o que, segundo ele, permite avaliar a coerência desses discursos e favorece a compreensão de seu papel ideológico. Cameron e Stelma (2004, p. 115) sustentam que cada discurso inclui grupos (clusters) de metáforas, e que esses agrupamentos metafóricos "assumem um papel importante no desdobramento discursivo".

É possível agrupar em seis chaves as 48 metáforas conceituais levantadas a partir das 431 expressões metafóricas mapeadas nos 105 textos do corpus, e dessas seis chaves, cinco retornam na matriz com a interseção 'deslocamentos + permanências da PSR na cidade' $x$ 'esquema de imagem', ${ }^{8}$ sendo bastante mais produtivas as chaves física e territorial:

\footnotetext{
${ }^{8}$ A chave conceitual ausente nesse corte temático é a chave sensorial. Esta chave é bastante concentrada na temática da chamada 'cracolândia', o que permite sugerir que é o aspecto drogadição ligado à PSR que se representa como algo a ser percebido sensorialmente. Isso será discutido em outro artigo.
} 
TABELA 2 - Consulta em matriz de codificação: células de interseção em Chaves conceituais $x$ (Deslocamentos + Permanências $x$ Esquema de Imagem)

\begin{tabular}{l|c}
\cline { 2 - 2 } & $\begin{array}{c}\text { Interseção: Deslocamentos }+ \\
\text { Permanências / Esquema de Imagem }\end{array}$ \\
\hline CHAVE BIOLÓGICA & 7 \\
\hline CHAVE CONFLITO & 6 \\
\hline CHAVE FÍSICA & 40 \\
\hline CHAVE INCÔMODO & 5 \\
\hline CHAVE TERRITORIAL & 36 \\
\hline
\end{tabular}

Mesmo considerado o corpus total de 105 textos e suas 431 expressões metafóricas nas 10 temáticas, a chave física está bastante concentrada na temática de deslocamentos da PSR na cidade, e a chave territorial é a mais relevante no corpus, sendo recorrente nas 10 temáticas. Esse espraiamento permite concluir que a questão territorial é um aspecto central à representação metafórica de APP dirigidas à PSR na FSP. As temáticas de território ligam-se às de conflito, como nas metáforas que interpretam a situação de rua como invasão humana e como esconderijo. O principal efeito dessa chave é interpretar a situação de rua como uma questão territorial: trata-se do espaço que ocupa, trata-se de 'apropriação do espaço público', e é isso o que se representa como questão. Nessa chave interpretativa, as APP dirigidas à PSR são uma questão de encaminhamento - a pessoa estando "sem rumo", "enjaulada" em seu problema interpretado como individual, deverá ser 'encaminhada'. A chave física complementa esse sentido, pois quando se associa a discurso desumanizante da PSR, a reifica e não a reconhece como sujeito de direitos, e daí seu deslocamento forçado pode ser naturalizado. ${ }^{9}$

\footnotetext{
${ }^{9}$ Quanto às outras três chaves conceituais identificadas nesse recorte temático, a chave biológica pode ser associada a discurso de defesa da (saúde da) cidade (entendida como ser vivo) de uma ameaça representada como sendo a situação de rua e a drogadição a ela associada (epidemia, doença) - portanto, a discurso de risco (epidemiológico, na lógica metafórica); a chave conflito, sendo de natureza bélica, reforça a interpretação da defesa da cidade; a chave incômodo, ligada a discursos higienistas, reifica a situação de rua.
} 
Já sabemos que as atitudes sociais a respeito de grupos minorizados influenciam as escolhas semânticas e lexicais apropriadas em sua representação discursiva (VAN DIJK, 2005), e esta por sua vez retorna a influência sobre as atitudes sociais (FAIRCLOUGH, 2001). Nosso corpus de metáforas reproduzidas nos textos da FSP confirma uma representação objetificante da PSR, representada em papel passivo como alvo de APP de encaminhamento, que restringem ou forçam seus movimentos e permanências na cidade, exceto quando são agentes de ações interpretadas como inconvenientes ou ameaçadoras, quando sua responsabilidade individual é enfatizada em termos de incômodo ou risco.

\section{Considerações finais}

Charteris-Black (2004, p. 10) reforça que para entender por que uma metáfora é preferida a outra, precisamos necessariamente considerar os contextos específicos em que são produzidas e os propósitos comunicativos que podem a elas ser associados, pois "as metáforas não são uma exigência do sistema semântico, mas são questões de escolha da/o falante". Assim, para compreender as escolhas da FSP ao representar a PSR e as APP a ela dirigidas, quando se trata de seus deslocamentos e permanências, precisamos atentar para escopos editoriais e interesses a que essa empresa de mídia se conecta. Olhar para textos que representam interesses do mercado imobiliário, por exemplo, pode ajudar.

$\mathrm{Na} F S P$, em textos relacionados a APP dirigidas à PSR, lê-se algo como "O Nova Luz é para a cidade recuperar área degradada, repleta de equipamentos fundamentais, com baixa densidade e localização privilegiada. É a primeira grande revitalização na cidade". Ao atribuir "baixa densidade" à região, ignora-se toda uma população, que é orientada a "procurar outro lugar, porque a área está sendo revitalizada". A isso se somam os sentidos da situação de rua como usurpação voluntária do espaço público ("manter o espaço público livre de usurpadores"). Ocultase a natureza social perversa da questão, quando se decide responsabilizar apenas o indivíduo, como se a situação de rua (sempre) fosse mesmo algo que se escolhesse diante de um cardápio de outras possibilidades. Sobre isso, Ávilla e Molina (2017, p. 61) sustentam que "a naturalização da situação de rua é parte de uma estratégia das políticas neoliberais, dado que permite legitimar a exclusão e justificar medidas políticas 
assistencialistas ou expulsivas que não levam em conta as determinações estruturais e históricas".

Esses sentidos servem para justificar APP desumanizantes, que possam, o mais rápido possível e ao menor custo, liberar uma área para exploração comercial, o que se chama comedidamente "revitalização". Isso se realiza mediante a 'internação' de pessoas em locais inadequados para o tratamento de seus problemas de saúde, ou sua simples expulsão para outros territórios comercialmente menos relevantes. Pouco se questiona a qualidade dos abrigos ofertados, mas repetidas vezes se questiona a decisão das pessoas de não usarem os albergues. Por isso, concordo com Charteris-Black (2004, p. 247) quando reforça o caráter ideológico das escolhas metafóricas em muitos casos, chamando atenção para sua natureza pragmática, já que "[a]s mesmas noções poderiam ter sido comunicadas utilizando-se metáforas diferentes, que carregassem ideologias diferentes, e as mesmas metáforas também podem ser empregadas de diferentes maneiras, de acordo com a perspectiva adotada".

Entendendo que o uso dessas metáforas tem força persuasiva não transparente - uma "função persuasiva subjacente", nos termos de Charteris-Black (2004, p. 9), vinculada à opacidade do discurso, nos termos de Fairclough (2010) -, sua relevância ao propor ao debate certas chaves interpretativas não deve ser minimizada. E isso ainda se soma à vantagem de as coisas não serem ditas abertamente, reduzindo o risco de se expressarem explicitamente sentidos como os decorrentes das metáforas conceituais que mapeamos. Além de atribuir à PSR sentidos tão crus como o de ser animalizada ou considerada coisa, inimigo, doença, as metáforas, escolhidas nesse contínuo movimento de reforço de um texto depois do outro, também ocultam outros sentidos - como o de ser humano, o de ter direitos, o de ser cidadão pleno. Ocultar esses sentidos é também o que permite defender as APP repressivas e violentas, noticiadas de forma naturalizada um dia depois do outro. 


\section{Agradecimentos}

Agradeço ao CNPq (PQ 304075/2014-0, PQ 301809/2017-8 e Universal 408220/2018-0) e à CAPES (PVEX 88881.172032/2018-01) o apoio aos projetos relacionados. Também à Universidad Pompeu Fabra por acolher o projeto "Representação de políticas públicas para população em situação de rua como gestão do território: metáforas espaciais na Folha de S. Paulo" em estágio pós-doutoral, e muito especialmente ao Dr. Teun A. van Dijk por sua supervisão. Registro meu agradecimento às colegas e alunas da Universidade de Brasília, sobretudo às pesquisadoras que se vincularam (Dara Abreu, Lygia Vaz) e que se vinculam (Carolina Araújo, Daniele Mendonça, Ingrid Ramalho, Larissa Silva e Gabriella Rodrigues) ao grupo de pesquisa em torno desses projetos.

\section{Referências}

ACOSTA, M. P. T. Metáfora como categoria epistemológica e analítica. In: RESENDE, V. M.; ARAÚJO, C. L. (Org.). Discurso e pobreza. Campinas: Pontes, 2018. p. 13-44.

ÁVILLA, H.; MOLINA, L. A situação de rua como problemática social estrutural nas cidades. In: RESENDE, V. M.; SILVA, R. B. (org.). Diálogos sobre mobilização e políticas públicas: academia e movimentos sociais. Campinas: Pontes, 2017. p. 59-86.

BHASKAR, R. Societies. In: ARCHER, M. et al. (org.). Critical Realism. Essencial readings. London: Routledge, 1998. p. 206-257.

CALDEIRA, T. P. R. Cidade de muros: crime, segregação e cidadania em São Paulo. São Paulo: Editora 34; EdUSP, 2004.

CAMERON, L. J.; STELMA, J. H. Metaphor clusters in discourse. Journal of Applied Linguistics, Oxford, v. 1, n. 2, p. 107-136, 2004. Doi: https://doi.org/10.1558/japl.2004.1.2.107

CHARTERIS-BLACK, J. Corpus Approaches for Critical Metaphor Analysis. London: Palgrave, 2004. Doi: https://doi.org/10.1057/9780230000612

COWAN, J.; FEUCHT-HAVIAR, J. Prefácio. In: SACKS, S. (org.). Da metáfora. Campinas: EDUC; Pontes, 1992. 
DANCYGIER, B. Figurativeness, Conceptual Metaphor, and Blending. In: SEMINO, E; DEMJÉN, Z. The Routledge Handbook of Metaphor and Language. London: Routledge, 2016. p. 28-41.

DELGADO, M. El espacio público como ideología. Madrid: Catarata, 2015.

FAIRCLOUGH, N. Discurso e mudança social. Brasília: Editora UnB, 2001.

FAIRCLOUGH, N. Analysing Discourse: Textual Analysis for Social Research. London: Routledge, 2003. Doi: https://doi. org/10.4324/9780203697078

FAIRCLOUGH, N. Critical Discourse Analysis: The Critical Study of Language. 2. ed. New York: Longman, 2010.

GARNIER, J. P. Contra los espacios del poder. Barcelona: Virus, 2006.

LAKOFF, G.; JOHNSON, M. Metaphors We Live By. Chicago: The University of Chicago Press, 1980.

LI, Wei. Rethinking Critical Metaphor Analysis. International Journal of English Linguistics, Ontário, v. 6, n. 2, p. 92-96, 2016. Doi: https://doi. org/10.5539/ijel.v6n2p92

MASSEY, D. Concepts of Space and Power in Theory and in Political Practice. Documents d'Anàlisi Geogràfica, Girona; Barcelona, Espanha. v. 55, p. 15-26, 2009.

MENDES, P. H. A.; NASCIMENTO, M. Análise do processamento metafórico no discurso: metáforas da crise econômica e da corrupção política. Scripta, Belo Horizonte, v. 14, n. 26, p. 89-106, 2010.

MONTECINO, L. (org.). Memorias de la calle. Santiago do Chile: Editorial Cuarto Propio, 2018.

NAKANO, K.; MALTA CAMPOS, C.; ROLNIK, R. Dinâmica dos subespaços na área central de São Paulo. In: COMIN, A. A.; SOMEKH, N. (org.). Caminhos para o centro. São Paulo: PMSP; Cebrap; CEM, 2004. p. 123-158.

PARDO ABRIL, N. G. Cómo hacer análisis crítico del discurso. Bogotá: Universidad Nacional de Colômbia, 2007. 
PARDO ABRIL, N. G. Qué nos dicen? Qué vemos? Qué es pobreza?. Bogotá: Universidad Nacional de Colômbia, 2008.

PARDO, M. L. Latin-American Discourse Studies: State of the Art and New Perspectives. Journal of Multicultural Discourses, [S.l.], v. 5, n. 3, p. 183-192, 2010. Doi: https://doi.org/10.1080/17447143.2010.508526

PASCALE, C-M. (org.). Social Inequality \& the Politics of Representation: A Global Landscape. London: Sage, 2013.

RAMALHO, I. S.; RESENDE, V. M. O caso Edvan Lima e a corporeidade de pessoas em situação de rua em casos de violência: análise de dados do jornal Correioweb. Cadernos de Estudos Linguísticos, Campinas, v. 60, n. 3, p. 808-827, 2018. Doi: https://doi.org/10.20396/cel.v60i3.8652150

RESENDE, V. M. Representação de pessoas em situação de rua no jornalismo on-line: quais são as vozes convocadas para falar sobre a situação de rua? Revista de Estudos da Linguagem, Belo Horizonte, v. 26, n.3, p. 955-988, 2016. Doi: http://dx.doi.org/10.17851/22372083.24.3.955-988

RESENDE, V. M. Reflexões teóricas e epistemológicas quase excessivas de uma analista obstinada. In: RESENDE, V. M; REGIS, J. F. (org.). Outras perspectivas em análise de discurso crítica. Campinas: Pontes, 2017. p. 11-52.

RESENDE, V. M. Análise interdiscursiva de políticas públicas. Reflexão epistemológica. Revista Ámbitos, Sevilha, v. 39, p. 57-70, 2018.

RESENDE, V. M.; GOMES, M. C. A. Representação da situação de rua no jornalismo eletrônico em textos verbo-visuais - a violência em discurso no Correio Braziliense (2011-2013). Linguagem em (Dis) curso, Tubarão, SC, v. 18, n. 1, p. 165-191, 2018. Doi: https://doi.org/10.1590/1982-4017180110-8117

RESENDE, V. M.; MENDONÇA, D. G. População em situação de rua e políticas públicas: representações na Folha de São Paulo. Revista DELTA, São Paulo. No prelo. Aceito para publicação.

RESENDE, V. M.; RAMALHO, I. S. Representação midiática da violação de direitos e da violência contra pessoas em situação de rua no Correio Web. Calidoscópio, São Leopoldo, RS, v. 15, n. 3, p. 529-541, 2017. Doi: https://doi.org/10.4013/cld.2017.153.11 
ROLNIK, R. Guerra dos lugares: a colonização da terra e da moradia na era das finanças. São Paulo: Boitempo, 2016.

SALDANHA, A. Power-Geometry as Philosophy of Space. In: FEATHERSTONE, D.; PAINTER, J. (ed.). Spatial Politics: Essays for Doreen Massey. Oxford: Wiley-Blackwell, 2013. p. 44-55. Doi: https:// doi.org/10.1002/9781118278857.ch3

SANTOS, M. Por uma outra globalização. São Paulo: Record, 2006.

SEGATO, R. En busca de un léxico para teorizar la experiencia territorial contemporânea. Politika. Revista de Ciencias Sociales, España, v. 2, p. 129-148, 2006.

SMITH, N. La nueva frontera urbana: ciudad revanchista y gentrificación. Madrid: Traficantes de Sueños, 2012.

SOUZA, C. Políticas públicas: uma revisão de literatura. Sociologias, Porto Alegre, v. 8, n. 16, p. 20-45, 2006. Doi: https://doi.org/10.1590/ S1517-45222006000200003

VAN DIJK, T. Critical discourse analysis. In: TANNEN, D.; SCHIFFRIN, D.; HAMILTON, H. (org.). Handbook of Discourse Analysis. Oxford: Blackwell, 2001.p. 352-371.

VAN DIJK, T. Nuevo racismo y noticias: un enfoque discursivo. In: NASH, M.; TELLO, R.; BENACH, N. (org.). Inmigración, género y espacios urbanos. Los retos de la diversidad. Barcelona: Edicions Bellaterra, 2005. p. 33-55.

VAN DIJK, T. A. Society and Discourse. How Social Contexts Influence Text and Talk. Cambridge: Cambridge University Press, 2009. Doi: https://doi.org/10.1017/CBO9780511575273

VAN DIJK, T. A. Discourse-Cognition-Society. Current State and Prospects of the Socio-Cognitive Approach to Discourse. In: HART, C.; CAP, P. (org.). Contemporary Critical Discourse Studies. London; New York: Bloomsbury, 2014. p. 121-146.

VIEIRA, V. C.; RESENDE, V. M. Análise de discurso (para a) crítica: o texto como material de pesquisa. Campinas: Pontes, 2016.

WACQUANT, L. Os condenados da cidade. Rio de Janeiro: Revan, 2005. 